\title{
Benoît JEANJEAN et Bertrand LANÇON (traduction, notes et commentaires), Saint Jérome Chronique. Continuation de la Chronique d'Eusèbe, années 326-378
}

\section{Christine Bousquet-Labouérie}

\section{CpenEdition}

\section{Journals}

Édition électronique

URL : https://journals.openedition.org/abpo/554

DOI : $10.4000 / a b p o .554$

ISBN : 978-2-7535-1504-8

ISSN : 2108-6443

Éditeur

Presses universitaires de Rennes

Édition imprimée

Date de publication : 30 décembre 2006

Pagination : 197-198

ISBN : 978-2-7535-0405-9

ISSN : 0399-0826

\section{Référence électronique}

Christine Bousquet-Labouérie, «Benoît JEANJEAn et Bertrand Lançon (traduction, notes et

commentaires), Saint Jérome Chronique. Continuation de la Chronique d'Eusèbe, années 326-378 », Annales de Bretagne et des Pays de l'Ouest [En ligne], 113-4 | 2006, mis en ligne le 30 décembre 2008, consulté le 22 juillet 2022. URL : http://journals.openedition.org/abpo/554 ; DOI : https://doi.org/ $10.4000 / a b p o .554$

Ce document a été généré automatiquement le 22 juillet 2022.

Tous droits réservés 


\title{
Benoît JEANJEAN et Bertrand LANÇON (traduction, notes et commentaires), Saint Jérome Chronique. Continuation de la Chronique d'Eusèbe, années 326-378
}

\author{
Christine Bousquet-Labouérie
}

\section{RÉFÉRENCE}

Traduction, notes et commentaires de Bertrand Lançon, Rennes, PUR, 2004, 208 p.

\section{NOTE DE L'ÉDITEUR}

Cet ouvrage sur le site des Presses universitaires de Rennes : notice, documents et commande en ligne : http://www.pur-editions.fr/detail.php?idOuv=784

1 La publication de sources latines dans une édition bilingue est un moment toujours apprécié et appréciable pour les médiévistes. La chronique d'Eusèbe traduite et prolongée par Saint Jérôme participe de ces grands textes antiques passés dans le monde médiéval et c'est cette continuation que publie ce livre de Benoit Jeanjean et Bertrand Lançon. Le texte, composé pour les années 326-378 restitue les derniers grands soubresauts du monde païen et les moments décisifs dans le choix politique du christianisme: les figures de Constantin, mais aussi de Julien sont les deux phares politiques du basculement. Ils sont accompagnés par des figures tout aussi essentielles des évêques et des moines qui fournissent les premiers contingents de saints du monde chrétien. La période essentielle du $\mathrm{IV}^{\mathrm{e}}$ siècle dans la formation et l'affirmation d'un empire dont la norme devient chrétienne est aussi celle de la difficulté à traduire en 
termes dogmatiques les préceptes évangéliques : la première grande querelle trinitaire liée à Arius et tranchée par le concile de Nicée en 325 est restituée par Jérôme à travers quelques notations éparses. On l'aura compris, cette chronique fournit des matériaux bruts à l'historien de l'antiquité tardive qui trouvera matière à de multiples réflexions et pistes de travail. Ce premier apport essentiel est complété par un appareil critique de traduction mais aussi par les commentaires d'Hervé Inglebert sur les chrétiens et l'histoire universelle dans l'antiquité tardive: la rencontre entre la théologie chrétienne et l'universalité romaine a permis la création d'une histoire universelle chrétienne dans laquelle s'inscrit la chronique continuée par Jérôme. Trois autres grilles de lecture accompagnent le texte, elles sont dues à Benoît Jeanjean qui relit le rôle de Jérôme comme patron des chroniqueurs en langue latine et non pas seulement comme celui des traducteurs. Son rôle comme initiateur du genre "chronique » se manifeste tout au long du haut du Moyen Âge y compris chez des auteurs d'envergure plus locale ou plus restreinte. Enfin après le genre et la forme, Stéphane Ratti s'intéresse aux signes divins et à l'histoire politique qui apparaissent dans la chronique. Le lien entre les quarante-neuf prodiges de toutes sortes et les crises traversées par l'empire romain est tout autant la trace pérenne du modèle grec que le reflet de l'inquiétude personnelle de Jérôme devant une situation de guerre civile permanente. Bertrand Lançon, lui, traque l'émergence des saints dans cette chronique mais en élargissant son point de vue aux autres chroniques latines des $\mathrm{IV}^{\mathrm{e}}-\mathrm{VI} \mathrm{V}^{\mathrm{e}}$ siècles; le choix d'associer des chroniques sur deux siècles a l'objectif précis de fournir une réponse à une question simple mais essentielle; l'hagiographie devient-elle une catégorie historique dans l'antiquité tardive? Les premiers éléments de réponse manifestent, certes, que les saints commencent à peupler les notices des chroniques certes, mais celles-ci n'appartiennent pas au genre propre de l'hagiographie malgré la présence des nombreux critères de sainteté que l'auteur appelle d'un joli néologisme, « hagiosèmie ». Ces éléments de réflexion sont des pistes de travail pour les historiens qui trouveront là une source indispensable pour l'étude du IV siècle de notre ère, qui par la force des choses ne doit rien à saint Augustin, ce qui la rend particulièrement précieuse. La place de transition de Jérôme, souvent un peu masquée par les textes grecs antérieurs et par l'évêque d'Hippone qui écrase de son poids tutélaire toute tentative de comparaison méritait d'être à nouveau définie, voilà qui est chose faite et bien faite. 